\title{
IMPLIKASI KONSEP ISLAMISASI ILMU PENGETAHUAN ISMAIL RAJI AL-FARUQI
}

\section{Poppy Rachman}

Universitas Islam Zainul Hasan Genggong Probolinggo

poppyrachman.inzah@gmail.com

\begin{abstract}
This research is entitled Implications of the Concept of Islamization of Ismail RajiAl-Faruqi Science. Science is important in human life. God put knowledge as a matter that must not be abandoned. During this time the Islamic religion is believed to have a very important role in coloring the building of science. But in reality, the Muslim community seems to be forced to carry out secular teachings in life due to the swift currents of secularization. This condition is a concern of Islamic thinkers, because it can endanger the Islamic faith. It is in connection with this concern that ideas or ideas about the Islamization of science emerge as an attempt to neutralize the influence of modern western science. Al-Faruqi was one of the thinkers about Islamization. How is the concept of Islam? and what are the implications for life in Indonesia? The Islamization of knowledge is not only a discourse, but requires real implications to be useful for the wider community. Al-Faruqi has sought to realize the Islamization of knowledge by establishing Islamic study groups. The movement is carried out by sticking to the principles of monotheism so as not to deviate from religious teachings. Some developments have also taken place in Indonesia in response to the Islamization of science, including: the establishment of Islamic-based schools and the rise of cooperatives and Islamic banks.
\end{abstract}

Keywords: Islamization, Science, Al-Faruqi.

https://ejournal.unzah.ac.id/index.php/humanistika 


\section{Abstrak}

Penelitian ini berjudul Implikasi Konsep Islamisasi Ilmu Pengetahuan Ismail RajiAl-Faruqi. Ilmu pengetahuan merupakan hal yang penting dalam kehidupan manusia. Allah menempatkan ilmu sebagai suatu hal yang tidak boleh ditinggalkan. Selama ini agama Islam diyakini memiliki peranan yang sangat penting dalam mewarnai bangunan ilmu pengetahuan. Namun kenyataannya, masyarakat muslim seolah dipaksa untuk melaksanakan ajaran sekuler dalam kehidupan lantaran derasnya arus sekularisasi. Kondisi inilah yang menjadi keprihatinan para pemikir Islam, sebab bisa membahayakan keimanan Islam. Berkaitan dengan keprihatinan itulah muncul ide atau gagasan mengenai islamisasi ilmu pengetahuan sebagai upaya untuk menetralisir pengaruh sains barat modern. Al-Faruqi adalah salah seorang pemikir tentang islamisasi. Bagaimana konsep islamisasinya? serta apa implikasinya dalam kehidupan di Indonesia? Islamisasi pengetahuan tidak hanya sebagai wacana, tetapi membutuhkan implikasi nyata agar berguna bagi masyarakat luas. Al-Faruqi telah berupaya merealisasikan islamisasi pengetahuan dengan mendirikan kelompok-kelompok studi Islam. Gerakan tersebut dilakukan dengan tetap berprinsip pada ajaran tauhid agar tidak menyimpang dari ajaran agama. Beberapa perkembangan juga terjadi di Indonesia sebagai tanggapan dari Islamisasi ilmu, diantaranya: berdirinya sekolah- sekolah berbasis Islam dan maraknya koperasi-koperasi serta bank-bank syariah.

Kata Kunci :Islamisasi, IlmuPengetahuan, Al-Faruqi. 
Implikasi Konsep Islamisasi Ilmu Pengetahuan Ismail Raji Al-Faruqi PENDAHULUAN

Pergulatan sebuah ilmu pengetahuan kini sangatlah terasa. Dimana pergulatan ini dirasakan ketika science mengalami perubahan yang begitu pesat dan diiringi oleh munculnya ilmu-ilmu baru. Tidak sedikit klaimklaim atas ilmu pengetahuan hingga sampai pada dewasa ini. seperti halnya klaim bahwa ilmu pengetahuan itu bebas nilai, ilmu pengetahuan itu hanya ilmu alam yang sifatnya pasti hingga sampai klaim yang mengatakan bahwa ilmu pengetahuan merupakan hasil dari peradaban barat. Yang notabenenya berangkat dari asumsi para tokoh dan pencetus ilmu pengetahuan tersebut berasal dari Barat. Hal ini seakan-akan mengklaim ilmu pengetahuan tersebut hanyalah milik dan muncul dari peradaban Barat.

Mengenai definisi dari ilmu pengetahuan menurut Rene Descartes sebagai pencetus Filsafat Modern telah melahirkan revolusi paham keagamaan bahwa pada dasarnya manusia itu merdeka, sekaligus melahirkan revolusi pemikiran yang pada akhirnya menimbulkan revolusi ilmu pengetahuan. Revolusi ilmu pengetahuan ini ternyata juga menimbulkan masalah-masalah baru. Semangat untuk membebaskan diri dari tuhan ternyata menyebabkan agnotisisme terhadap agama, dan pada gilirannya menimbulkan sekularisme. Sementara itu revolusi ilmu pengetahuan dalam semangat non-agama dan bahkan anti-agama, menghasilkan paham bahwa ilmu pengetahuan secara inheren bersifat bebas nilai. ${ }^{1}$

Ada beberapa kelompok yang paling dirugikan akibat penerapan konsep sekularisasi ini. Mereka adalah kelompok-kelompok masyarakat yang memiliki ikatan moral dengan ajaran agamanya, terutama masyarakat muslim. Ketika mengikuti arus perkembangan sains modern dari barat, mereka secara sadar maupun terpaksa menggantikan nilai-nilai religius mereka dengan sekuler yang sangat kontras. Selama ini agama Islam

\footnotetext{
${ }^{1}$ Kuntowijoyo, Islam Sebagai Ilmu: Epistimologi, Metodologi dan Etika, (Yogyakarta: Tiara Wacana, 2007), hal. 114.
} 
diyakini memiliki peranan yang penting dalam mewarnai bangunan ilmu pengetahuan dan juga unsur-unsur lain yang terkait. Namun kenyataannya, masyarakat muslim seolah dipaksa untuk melaksanakan ajaran sekuler dalam kehidupan lantaran derasnya arus sekularisasi. Kondisi inilah yang menjadi keprihatinan para pemikir Islam, sebab bisa membahayakan keimanan (akidah) Islam. ${ }^{2}$

Menurut al-Faruqi, westernisasi telah membawa efek negatif bagiumat Islam. Di satu pihak umat Islam telah berkenalan dengan peradaban barat modern, tetapi di pihak lain mereka kehilangan pijakan yang kokoh yaitu pedoman hidup yang bersumber moral agama. Umat Islam sulit untuk menentukan pilihan arah yang tepat. Dengan demikian, umat Islam akhirnya terkesan mengambil sikap mendua. Pandangan dualisme yang demikian ini menjadi penyebab dari kemunduran yang dialami umat Islam, untuk menghilangkan dualisme ini maka pengetahuan harus diislamisasikan. ${ }^{3}$

Dalam tulisan ini, akan berusaha memaparkan bagaimana konsep danimplikasipemikiran Ismail Raji al-Faruqi mengenai islamisasi ilmu pengetahuan. Terdapat empat bahasan utama: Pertama, biografi Ismail Raji al-Faruqi. Kedua, latar belakang pemikiran Islamisasi Ismail Raji al-Faruqi. Ketiga, konsep islamisasi ilmual-Faruqi. Keempat, implikasiislamisasiilmupengetahuan.

\section{PEMBAHASAN}

${ }^{2}$ Mujamil Qamar, Epistimologi Pendidikan Islam dari Metode Rasional hingga Metode Kritik, (Jakarta: Erlangga, 2005), hal. 115.

${ }^{3}$ Ramayulis dan Syamsul Nizar, Ensiklopedi Tokoh Pendidikan Islam, Mengenal Tokoh Pendidikan Islam di Dunia Islam dan di Indonesia, (Ciputat: Quantum Teaching, 2005) hal. 110. 
Implikasi Konsep Islamisasi Ilmu Pengetahuan Ismail Raji Al-Faruqi

\section{A. Biografi Ismail Raji Al-Faruqi}

Ismail Raji Al-Faruqi yang lebih terkenal dengan nama Al-Faruqi lahir di daerah Jaffa, Palestina pada tanggal 1 Januari 1921. Ayahnya adalah seorang qhadi di Palestina. Al-Faruqi mulai pendidikan dasarnya di College des ferese, Libanon, yang menggunakan bahasa Prancis sebagai bahasa pengantarnya sejak 1926 hingga 1936. Pendidikan tinggi ia tempuh di American University Beirut. Pada 1941, setelah meraih gelar Bachelor of Arts (BA), ia bekerja sebagai pegawai pemerintah (PNS) Palestina di bawah mandat Inggris. Empat tahun kemudian, karena kepemimpinannya yang menonjol, Al-Faruqi diangkat sebagi Gubernur di Provinsi Galelia, Palestina, pada usia 24 tahun. Namun jabatan ini tidak lama diembannya, karena tahun 1947 provinsi tersebut jatuh ketangan Israel sehingga ia hijrah ke Amerika. Setahun di Amerika Faruqi melanjutkan studinya di Indiana University sampai meraih gelar Master dalam bidang filsafat, tahun 1949. Dua tahun kemudian ia meraih gelar master kedua dalam bidang yang sama dari Universitas Harvard. ${ }^{4}$

Pada tahun 1952 Al-Faruqi meraih gelar Ph.D dari Universitas Indian, dengan disertasi berjudul On Justifying the God: Metaphysic and Epistemology of Value (tentang pembenaran Tuhan, Metafisika dan epistimologi nilai). Namun, apa yang dicapai ini tidak memuaskannya. Karna itu ia kemudian pergi ke Mesir untuk lebih mendalami ilmu-ilmu keislaman di Universitas al-Azhar Kairo selama empat tahun. ${ }^{5}$ Usai studi Islam di Kairo, Al-Faruqi mulai berkiprah di dunia kampus dengan mengajar di Universitas McGill Montreal Kanada pada tahun 1959 selama 2 tahun. Pada tahun 1962 Al-Faruqi pindah ke Karachi Pakistan untuk ikut terlibat dalam kegiatan Central Institute for Islamic Research. Setahun kemudian tepatnya tahun 1963 Al-Faruqi kembali ke AS dan memberikan kuliah di Fakultas Agama Universitas Chicago dan selanjutnya pindah ke program pengkajian Islam di Universitas Syracuse New York. Pada tahun

${ }^{4}$ Budi Handrianto, Islamisasi Sains: Sebuah Upaya Mengislamkan Sains Barat Modern (Yogyakarta: Pustaka Al-Kausar, Cet.1, 2010)

${ }^{5}$ Khudori Soleh, W acana Baru Filsafat Islam. (Yogyakarta: Pustaka Pelajar. 2012) 
1968 ia pindah ke Universitas Temple Philadelphia sebagai guru besar dan mendirikan pusat kajian Islam di institute tersebut. Al-Faruqi mengabdikan ilmunya di kampus hingga akhir hayatnya pada 27 Mei 1986 di Philadelphia. ${ }^{6}$

Selama hidupnya Al-Faruqi sangat produktif, ia banyak meninggalkan karya tulis. tercatat tidak kurang dari 100 artikel dan 25 judul buku, yang mencakup berbagai persoalan, antara lain, etika, seni, sosiologi, kebudayaan, metafisika, dan politik. Di antara bukunya adalah Ushul alSyhyuniyah fi al-Din al-Yahudi (1963) Historical Atlas of Religion of the World (1974), Islamic and culture (1980), Islamization of Knowlegde General Principles and Workplan (1982) Tauhid Its Implications for Thought and Life (1982), Cultural Atlas of Islam (1982), Christian Ethics, Trealogue of Abraham Faith, dan Atlas of Islamic Culture and Civilization. ${ }^{7}$

Ismail Raji Al-Faruqi wafat pada tanggal 17 Ramadhan $1406 \mathrm{H}$ atau 27 Mei 1986. Dia dibunuh oleh orang yang tak dikenal, di wilayah Cheltelham, Philadelphia (Al-Faruqi dan Lamnya Al-Faruqi, 1998: 8). Maka untuk mengenang beliau, The Internasional Institut of Islam Though (IIIT), Washington DC, tahun 1993 memberi penghargaan bagi karya-karya akademis yang istimewa. Penghargaan ini dikenal sebagai Ismail Al-Faruqi Award".

\section{B. Latar Belakang Gagasan Al-faruqi Tentang Islamisasi Ilmu}

Secara historis, umat Islam telah melintasi perjalanan yang cukup panjang, dan bahkan menghasilkan kekayaan pemikiran yang luar biasa

${ }^{6}$ Budi Handrianto, Islamisasi Sains: Sebuah Upaya Mengislamkan Sains Barat Modern (Yogyakarta: Pustaka Al-Kausar, Cet.1, 2010)

${ }^{7}$ Khudori Soleh, Filsafat Islam dari klasik hingga kontemporer, (Yogyakarta: Ar-Ruzz Media, 2013) 
Implikasi Konsep Islamisasi Ilmu Pengetahuan Ismail Raji Al-Faruqi terlebih pada masa klasik. Namun mulai pada abad ke-13 peradaban Islam mengalami situasi yang stagnan.

Menurut Al-Faruqi meskipun kaum muslimin sudah memakai sistem pendidikan sekuler Barat, baik di lingkungan universitas maupun cendekiawan belum mampu menghasilkan sesuatu yang sebanding dengan kreativitas dan kehebatan Barat. Hal ini disebabkan karena dunia Islam tidak memiliki ruh wawasan vertikal yaitu wawasan Islam. Gejala tersebut dirasakan Al-Faruqi sebagai apa yang disebut dengan "the lack of vision". Kehilangan yang jelas tentang sesuatu yang harus diperjuangkan sampai berhasil. $^{8}$

Factor utama yang melatarbelakangi munculnya gagasan Islamisasi Ilmu pengetahuan Al-Faruqi adalah kondisi kehidupan umat Islam yang dinilainya terbelakang dalam berbagai aspek. Baginya solusi terbaik keluar dari jeratan tersebut adalah dengan cara merekonstruksi sikap, pola hidup, dan pola pikir umat Islam melalui paradigma keilmuan dan pendidikan yang sesuai dengan nilai-nilai Islam.

Ada tiga faktor yang mewarnai lahirnya gagasan islamisasi ilmu al-faruqi yaitu: ${ }^{9}$

1. Krisis pemikiran atau malaisme yang melanda umat Islam. Malaisme tersebut dianggap Al-Faruqi sebagai sumber berbagai krisis yang dialami umat Islam mulai dari krisis politik, ekonomi, hingga agama dan budaya. Keterpurukan umat Islam dalam berbagai bidang kehidupan tersebut, menempatkan umat Islam berada di posisi terbawah dari bangsa-bangsa lain. Dalam bidang politik kekuatan kolonial telah berhasil memecah belah umat Islam menjadi kurang lebih 50 negara yang berdiri sendiri sendiri, dan saling menghantam diantara mereka. Sementara dalam bidang ekonomi umat Islam belum

8Zuhdiyah. 2016. Islamisasi Ilmu Ismail Raji Al-Faruqi. Jurnal Tadrib, Volume II, Nomor 2, Desember 2016. Hlm 1-18.

'Wan Mohd nor wan daud, Filsafat dan praktike pendidikan Islam syed M. Naquib Al-Attas, ( Mizan: cetakan Pertama: 2003)

Humanistika: Vol. 6 No 22020 
maju sebagaimana bangsa-bangsa lain. Disisi lain, selama berabad-abad kemerosotan kaum muslimin menyebabkan merebaknya buta huruf, kebodohan, dan takhayul diantara mereka. Dengan kata lain umat Islam hanya menjadi pengekor Barat.

2. System pendidikan umat Islam yang dualistik. Modernisasi Barat sangat berpengaruh terhadap kemajuan dunia pendidikan, namun keadaan pendidikan di dunia Islam dalam pandangan Al-Faruqi merupakan fenomena yang terburuk. System pendidikan dinegaranegara Muslim tercerabut dari tradisi Islam serta hanya merupakan karikatur dari prototype system pendidikan barat. Dalam pemikiran AlFaruqi sekolah-sekolah umum warisan pemerinatah kolonial semakin dominan, sekuler serta jauh dari nilai-nilai Islam. Tidak hanya itu, pengelolaan pendidikan di dunia Islam tidak didukung visi yang jelas dan komitmen pada standar mutu, hingga gagal melahirkan sarjana kreatif.

3. Latar pendidikan dan pengalaman mengajar Al-Faruqi juga memiliki andil dalam mewarnai gagasan pemikiran islamisasinya. Pendidikan yang diperolehnya merupakan perpaduan dari pendidikan Islam dan pendidikan Barat sekuler. Al-Faruqi hidup di lembaga-lembaga ternama di dunia yang proses pembelajarannya masih memakai sistem dikotomi pada waktu itu, seperti Universitas Al Azhar Kairo Mesir yang dikenal hanya mengkaji keislaman, sementara di Amirecan University of Beirut sistem pendidikannya kebarat-baratan.

Dari pemaparandiatasdapatdipahamibahwaadatiga factor yang mewarnai lahirnya gagasan islamisasi ilmu al-faruqiyakni krisis pemikiran atau malaisme yang melanda umat Islam, system pendidikan umat Islam yang dualistikdanLatar pendidikan dan pengalaman mengajar Al-Faruqi juga memiliki andil dalam mewarnai gagasan pemikiran islamisasinya. Bagi AlFaruqi solusi terbaik keluar dari masalah tersebut adalah dengan merekonstruksi sikap, pola hidup, dan pola pikir umat Islam melalui 
Implikasi Konsep Islamisasi Ilmu Pengetahuan Ismail Raji Al-Faruqi sudutpandangtentangkeilmuan dan pendidikan yang sesuai dengan ajarandannilai-nilai Islam

\section{Konsep Islamisasi Ilmu menurut Al-Faruqi}

Untuk mempermudah proses Islamisasi Al-Faruqi mengemukakan langkah-langkah yang harus dilakukan, yaitu: ${ }^{10}$

1. Penguasaan disiplin ilmu moderen: penguraian kategoris. Disiplin ilmu dalam tingkat kemajuannya sekarang di Barat harus dipecahpecah menjadi kategori-kategori, prinsip-prinsip, metodologimetodologi, problema-problema dan tema-tema. Penguraian tersebut harus mencerminkan daftar isi sebuah pelajaran. Hasil uraian harus berbentuk kalimat-kalimat yang memperjelas istilah-istilah teknis, menerangkan kategori-kategori, prinsip, problema dan tema pokok disiplin ilmu-ilmu Barat dalam puncaknya.

2. Survei disiplin ilmu. Semua disiplin ilmu harus disurvei dan di eseiesei harus ditulis dalam bentuk bagan mengenai asal-usul dan perkembangannya beserta pertumbuhan metodologisnya, perluasan cakrawala wawasannya dan tak lupa membangun pemikiran yang diberikan oleh para tokoh utamanya. Langkah ini bertujuan menetapkan pemahaman muslim akan disiplin ilmu yang dikembangkan di dunia Barat.

3. Penguasaan terhadap khazanah Islam. Khazanah Islam harus dikuasai dengan cara yang sama. Tetapi disini, apa yang diperlukan adalah ontologi warisan pemikir muslim yang berkaitan dengan disiplin ilmu.

4. Penguasaan terhadap khazanah Islam untuk tahap analisa. Jika ontologi-ontologi telah disiapkan, khazanah pemikir Islam harus dianalisa dari perspektif masalah-masalah masa kini.

${ }^{10}$ Ismail Raji al-Faruqi, Islamization of Knowledge (Virginia: International Institute of Islamic Thought, 1989. 
5. Penentuan relevensi spesifik untuk setiap disiplin ilmu. Relevensi dapat ditetapkan dengan mengajukan tiga persoalan. Pertama, apa yang telah disumbangkan oleh Islam, mulai dari Al- Qur'an hingga pemikir-pemikir kaum modernis, dalam keseluruhan masalah yang telah dicakup dalam disiplin-disiplin moderen. Kedua, seberapa besar sumbangan itu jika dibandingkan dengan hasil-hasil yang telah diperoleh oleh disiplin moderen tersebut. Ketiga, apabila ada bidang-bidang masalah yang sedikit diperhatikan atau sama sekali tidak diperhatikan oleh khazanah Islam, ke arah mana kaum muslim harus mengusahakan untuk mengisi kekurangan itu, juga memformulasikan masalah-masalah, dan memperluas visi disiplin tersebut.

6. Penilaian kritis terhadap disiplin moderen. Jika relevensi Islam telah disusun, maka ia harus dinilai dan dianalisa dari titik pijak Islam.

7. Penilaian kritis terhadap khazanah Islam. Sumbangan khazanah Islam untuk setiap bidang kegiatan manusia harus dianalisa dan relevansi kontemporernya harus dirumuskan.

8. Survei mengenai problem-problem terbesar umat Islam. Suatu studi sistematis harus dibuat tentang masalah-masalah politik, sosial ekonomi, inteltektual, kultural, moral dan spritual dari kaum muslim.

9. Survei mengenai problem-problem umat manusia. Suatu studi yang sama, kali ini difokuskan pada seluruh umat manusia, harus dilaksanakan.

10. Analisa kreatif dan sintesa. Pada tahap ini sarjana muslim harus sudah siap melakukan sintesa antara khazanah-khazanah Islam dan disiplin moderen, serta untuk menjembatani jurang kemandegan berabad-abad. Dari sini khazanah pemikir Islam harus disambungkan dengan prestasi-prestasi moderen, dan harus menggerakkan tapal batas ilmu pengetahuan ke horison yang lebih luas daripada yang sudah dicapai disiplin-disiplin moderen. 
Implikasi Konsep Islamisasi Ilmu Pengetahuan Ismail Raji Al-Faruqi

11. Merumuskan kembali disiplin-disiplin ilmu dalam kerangka kerja (framework) Islam. Sekali keseimbangan antara khazanah Islam dengan disiplin moderen telah dicapai buku-buku teks universitas harus ditulis untuk menuangkan kembali disiplin moderen dalam terbitan Islam.

12. Penyebarluasan ilmu pengetahuan yang sudah diislamkan.

\section{ImplikasiKonsepIslamisasiIlmuPengetahuan Al-Faruqi}

Islamisasi pengetahuan tidak hanya sebagai wacana, tetapi membutuhkan implikasi nyata agar berguna bagi masyarakat luas. AlFaruqi telah berupaya merealisasikan islamisasi pengetahuan dengan mendirikan kelompok-kelompok studi Islam. Gerakan tersebut dilakukan dengan tetap berprinsip pada ajaran tauhid agar tidak menyimpang dari ajaran agama.

1) ImplikasiIslamisasiIlmuPengetahuanLingkupInternasioanl

Islamisasi pengetahuan tidak cukup hanya sebagai sebuah kajian,publikasi dari hasil kajian merupakan langkah dalam menyebarluaskan Islamisasi pengetahuan kepada masyarakat luas untuk dikenal lebih dalam. Al-Faruqi sebagai penggagas islamisasi pengetahuan, memiliki semangat yang sangat besar dalam terciptanya ilmu-ilmu pengetahuan yang sesuai dengan kerangka berpikir Islam. Beliau mendirikan Departemen Islamic Studies sekaligus memimpinnya hingga akhir hayatnya.

Di samping pendirian Departemen Islamic Studies, al-Faruqi memperkenalkan studi-studi keislaman di beberapa perguruan tinggi Amerika. Lebih lanjut, beliau bersama dengan istrinya, Dr. Louis Lamya, membentuk kelompok-kelompok kajian Islam, seperti Muslem Student Association (MSA), American Academy of Religion (AAR), mendirikan Himpunan Ilmuwan Sosial Muslim (The Association of Muslem Social Scientist - AMSS), Islamic Society of North America (ISNA), menerbitkan jurnal American Journal of Islamic Social Sciences (AJISS), dan yang 
sangat menomental, beliau mendirikan Perguruan Tinggi Pemikiran Islam (The International Institue of Islamic Thought - IIIT). ${ }^{11}$

2) ImplikasiIslamisasiIlmuPengetahuan di Indonesia

Hegemoni sains dan teknologi Barat membawa pengaruh yangsangat besar terhadap gaya dan pandangan kehidupan masyarakat. Dalam sejarahnya, sains Barat modern dibangun atas dasar semangat kebebasan dan sebagai bentuk penentangan terhadap dominasi ajaran Kristen, sehingga menyebabkan pola pikir yang berlawanan dengan pemikiran agama Kristen sebagai antitesis. Dalam hal ini, sekularisasi merupakan misi yang paling mencolok yang disisipkan ke dalam sains Barat modern. ${ }^{12}$

Pada millenium ketiga ini, ilmu pengetahuan modern masih akan menjadi faktor dominan dalam kehidupan bangsa Indonesia. Secara potensial, ilmu bisa menjadi sangat destruktif maupun konstruktif, tergantung kepada bagaimana cara kita mengelolanya. Pengelolaan yang sesuai dengan habitat kultural bangsa Indonesia akan menjadikan ilmu pengetahuan berdaya guna secara maksimal sekaligus sebagai tanggung jawab moral setiap orang. ${ }^{13}$

Berdasarkan teori di atas, muncul keinginan dari para pembaru Islam untuk melakukan modernisasi sebagai upaya pengembalian Islam ke masa kejayaan. Modernisasi berasal dari kata modern yang berarti pembaruan. Lahirnya pembaruan tentu akan selalu beriringan dngan kemajuan ilmu

${ }^{11}$ Khudori Sholeh, Filsafat Islam dari Klasik hingga Kontemporer, (Yogjakarta: ArRuzz Media, 2016), hal. 257-258

${ }^{12}$ Mujamil Qomar, Epistemologi Pendidikan Islam dari Metode Rasional hingga Metode Kritik, (Jakarta: Penerbit Erlangga), hal. 114-115.

${ }^{13}$ Mulyadhi Kartanegara, Mengislamkan Nalar Sebuah Respons terhadap Modernitas (Jakarta: Penerbit Erlangga, 2007), hal. 1. 
Implikasi Konsep Islamisasi Ilmu Pengetahuan Ismail Raji Al-Faruqi pengetahuan dan teknologi yang berkembang saat itu, maka tidak mungkin aka nada pembaruan tanpa ada dukungan perkembangan ilmu pengetahuan.

Modernisasi mengandung arti gerakan-gerakan dan usaha-usaha untuk mengubah paham-paham, adat-istiadat dan institusi-institusi lama agar menjadi sesuai dengan keadaan baru yang ditimbulkan oleh ilmu pengetahuan dan teknologi modern. Di Indonesia sendiri, pembaruanpembaruan yang terjadi selalu mempunyai karakteristik yang berhubungan dengan keyakinan dan ilmu pengetahuan.

Beberapa modernisasi di Indonesia bisa kita lihat dari berkembangnya kurikulum pendidikan formal yang berbasis Islam. Berdirinya sekolahsekolah swasta yang mengintegrasikan antara ilmu agama dan ilmu umum sebagai wujud implikasi pembaruan yang bernafaskan Islamisasi, dengan tujuan mengembalikan identitas umat Islam ke masa kejayaan. Selain itu, banyaknya institusi keuangan yang berasaskan syariah Islam menjadi sangat popular bagi masyarakat Indonesia. Keberadaan badan zakat tidak luput dari tujuan pembaruan. Semua usaha tersebut dilakukan agar umat Islam tidak tertinggal dengan umat lain tanpa mengesampingkan keyakianan agama agar tidak menyimpang dari ajaran-ajaran dan nilai-nilai moral.

\section{KESIMPULAN}

al-Faruqi adalah salah seorang tokoh yang memiliki gagasan brilian dalam memecahkan persoalan yang dihadapi umat Islam. Idenya tidak lepas dari konsep tauhid, karena tauhid adalah esensi Islam yang mencakup seluruh aktifitas manusia. Begitu pun gagasannya mengenai islamisasi ilmu, Bagi al-Faruqi, islamisasi ilmu pengetahuan berarti mengislamkan ilmu pengetahuan modern dengan cara melakukan aktivitas keilmuan seperti eliminasi, perubahan, penafsiran kembali dan penyesuaian terhadap komponen-komponennya. Untuk mendukung idenya, al-Faruqi telah menyusun rangkaian kerja yang harus dilaksanakan. Meski terdapat pro- 
kontra namun tak dipungkiri gagasannya tersebut menjadi bahan kajian dan perjuangan umat Islam hingga kini.

Beberapa pembaruan kaitannya dengan Islamisasi di Indonesia terjadi di berbagai bidang kehidupan, antara lain:

1. Bidang pendidikan, maraknya sekolah-sekolah berbasis Islam seperti Pondok Pesantren Modern dan institusi pendidikan formal sebagai wujud pengembalian ilmu- ilmu modern ke dalam kerangka Islam.

2. Bidang ekonomi, dengan berdirinya berbagai macam koperasi dan bank syariah.

3. Bidang sosial, banyak didirikannya badan zakat sebagai wadah pembayaran pajak secara Islami yang secara umum menerima bantuan-bantuan untuk diteruskan kepada pihak-pihak yang membutuhkan.

\section{SARAN}

Mengingat pesatnya perkembangan ilmu dalam beberapa tahun terakhir, terkhusus perkembangan sektor perekonomian, perlu kiranya pembahasan yang lebih mendalam terkait islamisasi ilmu yang berkaitan dengan ekonomi. Banyak permasalahan yang terjadi di sektor perekonomian tersebut. Semua hal yang berkaitan dengan keuangan di islamisasikan namun kegiatan tersebut tidak terlepas dari praktek kapitalisme yang hanya merubah bungkusnya saja namun tetap menjalankan praktek riba dll. 
Implikasi Konsep Islamisasi Ilmu Pengetahuan Ismail Raji Al-Faruqi

\section{DAFTAR PUSTAKA}

Budi Handrianto, Islamisasi Sains: Sebuah Upaya Mengislamkan Sains Barat Modern (Yogyakarta: Pustaka Al-Kausar, Cet.1, 2010)

Ismail Raji al-Faruqi, Islamization of Knowledge (Virginia: International Institute of Islamic Thought, 1989.

Khudori Soleh, Wacana Baru Filsafat Islam. (Yogyakarta: Pustaka Pelajar. 2012)

Khudori Soleh, Filsafat Islam dari klasik hingga kontemporer, (Yogyakarta: Ar-Ruzz Media, 2013)

Kuntowijoyo, Islam Sebagai Ilmu: Epistimologi, Metodologi dan Etika, (Yogyakarta: Tiara Wacana, 2007), hal. 114.

Islam, M. H. (2019, November). Model Pendekatan Halaqotul MuAllimin Al-Islamiyah dalam Membentuk Kepribadian Yang Rahmatan Lil Alamin Sebagai Identitas Kebangsaan di Pondok Pesantren AlMashduqiah. In Proceedings of Annual Conference for Muslim Scholars (Vol. 3, No. 1, pp. 491-503).

Islam, M. H. (2020). TOLERANCE LIMITATION IN FACING RELIGIOUS DIVERSITY BASED ON THE TEACHING OF ISLAM. Nazhruna: Jurnal Pendidikan Islam, 3(1), 1-13. 
Islam, M. H., \& Aziz, A. (2020). Transformation of Pesantren in Maintaining Good Character. HUMANISTIKA: Jurnal Keislaman, 6(1), 35-48.

Mujamil Qamar, Epistimologi Pendidikan Islam dari Metode Rasional hingga Metode Kritik, (Jakarta: Erlangga, 2005), hal. 115.

Mulyadhi Kartanegara, Mengislamkan Nalar Sebuah Respons terhadap Modernitas (Jakarta: Penerbit Erlangga, 2007), hal. 1.

Ramayulis dan Syamsul Nizar, Ensiklopedi Tokoh Pendidikan Islam, Mengenal Tokoh Pendidikan Islam di Dunia Islam dan di Indonesia, (Ciputat: Quantum Teaching, 2005) hal. 110.

Razwan. 2012. Viewpoints; When the Islamisation Model doesn't Work. Jurnal Emerald Group Publishing Limited, Vol 3, No 1, 2012, hlm. $57-66$

Salafudin. 2013. Islamisasi Ilmu Pengetahuan. Jurnal Tarbiyah, Volume 11, Nomor 2, Desember 2013. Hlm 195-216.

Sholeh. 2017. Islamisasi Ilmu Pengetahuan (Konsep Pemikiran Ismail Raji Al-Faruqi dan Syed Muhammad Naquib Al-Attas). Jurnal AlHikmah, Volume 14, Nomor 2, Oktober 2017. Hlm 209-221.

Wan Mohd nor wan daud, Filsafat dan praktik pendidikan Islam syed M. Naquib Al-Attas, ( Mizan: cetakan Pertama: 2003) 
Implikasi Konsep Islamisasi Ilmu Pengetahuan Ismail Raji Al-Faruqi

Yusuf, Imtiyaz. 2012. Islam and Knowledge (Al Faruqi's Concept of Religion in Islamic Thought). (London: I.B. Tauris \& Co Ltd, 2012)

Zuhdiyah. 2016. Islamisasi Ilmu Ismail Raji Al-Faruqi. Jurnal Tadrib, Volume II, Nomor 2, Desember 2016. Hlm 1-18. 